\title{
Phytochemical characterization and evaluation of Antiurolithiatic activity of selected source plants of Pashanabheda
}

\author{
Sulaiman C. $T^{*}$, Jyothi C. K, Jinu Krishnan Unnithan G, Prabhukumar K. M and Indira Balachandran
}

\begin{abstract}
Background: Pashanabheda is an important Ayurvedic drug known for diuretic and lithotriptic properties. The botanical identity of this drug is controversial as many plants like Bergenia ciliata (BC), Rotula aquatica (RA), Aerva lanata $(\mathrm{AL})$ and Plectranthus amboinicus (PA) are being used as its source plants in different parts of India. This study aims at comparative phytochemical and pharmacological evaluation of various source plants of Pashanabheda.

Methods: Comparative phytochemical analysis and evaluation of Antiurolithiatic activity was carried out in selected medicinal plants used as Pashanabheda. Chemical profiling was done by HPTLC analysis and characterization of major constituents was done using liquid chromatography based tandem mass spectroscopic analysis. Antiurolithiatic activity was evaluated by ethylene glycol induced urolithiasis in experimental animal model.

Results: Phytochemical studies showed that there is no significant correlation on chemical constituents of selected species. Certain common bands were observed for BC and RA on HPTLC profiling. Tandem mass spectroscopic characterization of various species showed presence of several polyphenolics in selected species. Both Bergenia ciliata and A. lanata possessed substantial antiurolithiatic activity compared to other species. A. lanata extract at doses of 100 and $200 \mathrm{mg} / \mathrm{kg}$, showed significant activity against ethylene glycol induced changes serum and urine biochemistry and also significantly prevented ethylene glycol induced damage to nephrons in experimental animals.
\end{abstract}

Conclusions: Aerva lanata contains many active phytochemicals and showed significant antiurolithiatic activity. The findings of this study may lead to the possibility of considering Aerva lanata as a validated alternative source for Pashanabheda.

Keywords: Pashanabheda, Bergenia ciliata, Rotula aquatica, Aerva lanata, Plectranthus amboinicus, HPTLC, LC/MS, Antiurolithiatic activity

\section{Introduction}

Urolithiasis is a urinary stone disease involves the calcifications in the kidney, bladder, or urethra. It forms as a result of physicochemical or genetic imbalances leading to super saturation of the urine with stone-forming salts. In most of the urinary calculi cases, the conventional medicines do not work because the stones are too

*Correspondence: sulaimanct@aryavaidyasala.com; slmnct@gmail.com Phytochemistry division, Centre for Medicinal Plants Research, Arya Vaidya Sala, Kerala, Kottakkal, India large or get trapped within the urinary system. In these cases, patients have to treat with modern interventional procedures which are not easily assessable, and almost not suitable for patients with high urinary stone recurrence rate. On this context, herbal medicines are found to be effective, as well as easily available and economical. Medicinal plants used in various traditional systems of medicines have been reported to possess antiurolithiatic activity [1, 2]. Pashanabheda is an important antiurolithiatic drugs used in Ayurveda in the treatment of urinary calculi [3]. The plant source of Pashanabheda 
is highly disputed. Different plants such as Bergenia ciliata, Rotula aquatica, Aerva lanata and Plectranthus amboinicus are being used as Pashanabheda in various parts of the country [4, 5]. However, Bergenia ciliata (Saxifragaceae) is widely used in north India and it is the official source plant of Pashanabheda as per Ayurvedic Pharmacopeia of India [6]. Urolithiasis denotes stones originating anywhere in the urinary tract, including the kidneys and bladder. It is assessed that about $12 \%$ of men and $55 \%$ of women have at least one occurrence of kidney stone during their life time [7]. In Ayurveda and folk medicine, many medicinal plants have been used to treat kidney calculi and have been shown to be effective [8]. Aerva lanata (Amaranthaceae) is an erect or prostrate undershrub found in the wild, throughout India. It is extensively used as Pashanabheda by most of the Ayurveda practitioners in South India for treating urinary dysfunctions $[8,9]$. Rotula aquatica, belonging to the family Boraginaceae, is a small branched shrub and is scattered throughout peninsular and Western Ghats of India in the sandy and rocky beds of streams and rivers. It is also used as Pashanabheda in certain parts of the country [10,11]. Plectranthus amboinicus is commonly known as Indian borage is an important medicinal plant used in Ayurveda and is considered as one of the sources of Pashanabheda $[4,12,13]$.

Although selected plants are being used as source plants of Pashanabheda, comparative phytochemical and antiurolithiatic activity are not yet reported and hence the present study is aimed at comparative chemical and pharmacological evaluation to identify alternative validated source for Pashanabheda.

\section{Materials and methods}

\section{Chemicals and reagents}

Chemicals such as gallic acid, quercetin and LC/MS grade solvents were obtained from Sigma Aldrich, Bangalore, India. All other reagents used were of analytical grade of Merck, Bangalore, India.

\section{Collection of plant materials}

Bergenia ciliata was obtained from Khari Baoli market, New Delhi. All other materials were collected from different zones of Kerala and were authenticated by the Plant
Systematics and Genetic Resources division, CMPR, Arya Vaidya Sala, Kottakkal, Kerala. The voucher specimens were deposited at CMPR Herbarium (Table 1).

\section{Extraction of materials}

The shade dried materials $(250 \mathrm{~g})$ of $B$. ciliata, A. lanata, $R$. aquatica and $P$. amboinicus were extracted with water using soxhlet extraction method for $72 \mathrm{~h}$. The extracts were evaporated to dryness at $40^{\circ} \mathrm{C}$ on a rotary evaporator (Heidolph, Germany) and it was stored under refrigerator until the various phytochemical and pharmacological studies.

\section{Estimation of Total polyphenols}

Polyphenols such as phenolics and flavonoids were estimated spectrophotometrically. The total phenolic content (TPC) was determined using Folin-Ciocalteu reagent. TPC was expressed as gallic acid equivalents (mg GAE) in mg / g of sample. Total flavonoid content (TFC) was measured by aluminium chloride colorimetric assay and expressed as mg quercetin equivalents (mg EQ) [14-16].

\section{High performance thin layer chromatographic (HPTLC) analysis}

HPTLC analysis was performed by Camag HPTLC system (Switzerland). Samples were applied using Camag ATS 4 on aluminium backed pre-coated silica gel $60 \mathrm{~F}_{254}$ HPTLC plate (Merck India). Mobile phase was standardized as toluene, ethyl acetate, methanol and formic acid in the ratio of $7: 3: 1: 0.2$. The chromatogram was developed in a saturated Twin Trough chromatographic chamber (Camag, Switzerland). The developed plate was visualized under UV $366 \mathrm{~nm}$ [17].

\section{LC/MS analysis}

LC-ESI/MS analysis was conducted on Agilent 6520 accurate mass Q-TOF LC/MS coupled with Agilent LC 1200 equipped with Extend-C18 column of $1.8 \mu \mathrm{m}$, $2.1 \times 50 \mathrm{~mm}$. Gradient elution was performed with $\mathrm{LC} /$ MS grade Acetonitrile (A) and $0.1 \%$ acetic acid in methanol (B) at a constant flow rate of $0.8 \mathrm{ml} / \mathrm{min}$, with an increase in the volume of $\mathrm{B} \% ; 5-20 \%, 12-30 \%, 19-40 \%$, $26-50 \%, 30-40 \%$. The MS analysis was performed using

Table 1 Sample details

\begin{tabular}{llll}
\hline SI. No. & Species Name & Locality & Voucher specimen No. \\
\hline 1 & Bergenia ciliata & Khari Baoli market, New Delhi & CMPR 11261 \\
2 & Aerva lanata & CMPR Campus, Kottakkal, Kerala & CMPR 11256 \\
3 & Rotula aquatica & Wayanad, Kerala & CMPR 11531 \\
4 & Plectranthus amboinicus & Kanjirappuzha, Palakkad, Kerala & CMPR 11258 \\
\hline
\end{tabular}


ESI in negative mode. The conditions for mass spectrometry were: drying gas (nitrogen) flow $5 \mathrm{~L} / \mathrm{min}$; nebulizer pressure 40 psig; drying gas temperature $325^{\circ} \mathrm{C}$; capillary voltage $3000 \mathrm{~V}$; fragmentor volt $125 \mathrm{~V}$; Oct RF Vpp $750 \mathrm{~V}$. The mass fragmentation was performed with varying collision energy $4 \mathrm{~V} / 100 \mathrm{DA}$ with an offset of $8 \mathrm{~V}[17,18]$.

\section{Acute Oral toxicity study}

The experiment was conducted on Wistar rats (females) weighing 139 - $155 \mathrm{~g}$ and aged 8 to 9 weeks obtained from the Animal House, J.S.S. College of Pharmacy, Ooty, Tamil Nadu, India. The rats were distributed into 5 groups with 6 animals in each group. The experimental procedures relating to the animals were authorized by Committee for the Purpose of Control and Supervision of Experiments on Animals (Approval No.: JSSCP/ IAEC/OT/Ph.D/Ph.Cology/06/2017-18) before starting the study and were conducted under the internationally accepted principles for laboratory animal use and care.

The extracts were prepared from plant material having a high safety margin and hence it was decided to use $2000 \mathrm{mg} / \mathrm{kg}$ (Limit test) for this study. The test item was prepared immediately prior to administration on respective treatment days. A quantity of $2 \mathrm{~g}$ of the test item was dissolved in distilled water and the volume made up to $10 \mathrm{ml}$ to get a test item concentration of $200 \mathrm{mg} /$ $\mathrm{ml}$. Homogeneity of the test item in the vehicle was maintained during treatment by constant stirring and mixing. The test substance was administered soon after preparation.

The prepared test item solutions were administered once orally as gavage to the fasted $(17-19 \mathrm{~h})$ rats at the dose volume of $10 \mathrm{ml} / \mathrm{kg}$ b.wt. to deliver a dose of $2000 \mathrm{mg} / \mathrm{kg}$ b.wt. Food was offered about 3-4h after dosing. Water was not withheld.

The treated rats were observed five times during day 1 (day of administration) i.e., at $30 \mathrm{~min}$ and four times at hourly (post-administration) intervals and once daily, and thereafter for a total of 14 days. The clinical signs were recorded on all working days. The body weights of rats were recorded on test day 1 (pre-administration), day 8 (7 days post-administration) and day 15 (14days postadministration. The rats were euthanized by using diethyl ether anesthesia and necropsied [17].

\section{Antiurolithiatic activity}

Adult Male Wistar albino rats were used for the study. The prior approval of the Institutional Animal Ethical Committee (Approval No. JSSCP/OT/IAEC/05/201819) was obtained for conducting this study. The animals were housed in polypropylene cages in a controlled environment (Temperature $23 \pm 2^{\circ} \mathrm{C}$ and $12 \mathrm{~h}$ dark and light cycle) with standard laboratory diet and water ad libitum in the animal house of the institution.

The plant extracts, $\mathrm{BC}, \mathrm{AL}, \mathrm{RA}$ and $\mathrm{PA}$ were prepared as solution in distilled water at two different concentrations of 10 and $20 \mathrm{mg} / \mathrm{ml}$ and administered at a dose volume of $10 \mathrm{ml} / \mathrm{kg}$, body weight as low $(100 \mathrm{mg} / \mathrm{kg})$ and high $(200 \mathrm{mg} / \mathrm{kg})$ dose, respectively.

Wistar rats were acclimated for 7 days before starting the experiment. Hyperoxaluria and calcium oxalate deposition in the kidneys was induced by ethylene glycol in the drinking water to a final concentration of $0.75 \%$, with $1 \%$ ammonium chloride for 3 days, to accelerate lithiasis. The rats were then given only ethylene glycol for 3 weeks. All the rats became nephrolithic by the end of the third week.

After randomization animals were divided into 10 groups of 6 each (Group I consisted of age matched normal animals). Group-1 \&2 served as Normal and Disease Control, respectively, and received only vehicle $(10 \mathrm{ml} /$ $\mathrm{kg}$, p.o.). Group-3 and 4 received $\mathrm{BC}$ extract at a dose of 100 and $200 \mathrm{mg} / \mathrm{kg}$, p.o., respectively. Group-5 and 6 received AL extract at a dose of 100 and $200 \mathrm{mg} / \mathrm{kg}$, p.o., respectively. Group -7 and 8 received RA extract at a dose of 100 and $200 \mathrm{mg} / \mathrm{kg}$, p.o., respectively. Group- 9 and 10 received PA extract at a dose of 100 and $200 \mathrm{mg} / \mathrm{kg}$, p.o., respectively. All groups were received assigned treatments for 28 days. During the treatment period all the groups except Group-1, received $0.75 \%$ ethylene glycol in drinking water.

During the study period clinical signs, mortality and weekly body weights were measured. On day 27 , urine was collected using metabolic cages to analyze urine biochemistry. At the end of the study blood was collected from retro-orbital plexus under light ether anesthesia and used for estimation of serum urea and creatinine levels. Following the blood collection animals were culled by deep ether anesthesia and kidneys were harvested and fixed in formal buffered saline $(10 \% \mathrm{v} / \mathrm{v})$ for histopathological analysis.

\section{Statistical analysis}

The data were represented as mean $\pm \mathrm{SD}$ and analyzed by one-way ANOVA followed by Dunnett's multiple comparison tests using Prism software (Version 4$). P$ values $\leq 0.05$ were considered significant.

\section{Results}

Estimation of Total polyphenolics (TPC\& TFC)

Total poly phenolic contents such as total phenolics (TPC) and Total flavonoids (TFC) of various source plants of Pashanabheda are presented in Table 2. TPC was calculated from calibration curve of gallic acid $\left(R^{2}=0.974\right)$ and TFC was calculated as quercetin 
Table 2 Total polyphenolics of various source plants of Pashanabheda

\begin{tabular}{lllll}
\hline $\begin{array}{l}\text { SI. No } \\
\text { Source plant } \\
\text { screened }\end{array}$ & TPC $(\mathbf{m g ~ G A E} / \mathbf{g})$ & $\mathrm{TFC}(\mathbf{m g}$ QE/g) & $\mathbf{F / P}$ \\
\hline 1 & B. ciliata & $128.44 \pm 0.95$ & $28.84 \pm 0.26$ & 0.22 \\
2 & R. aquatica & $17.24 \pm 0.16$ & $8.38 \pm 0.15$ & 0.48 \\
3 & A. lanata & $2.15 \pm 0.12$ & $1.48 \pm 0.36$ & 0.68 \\
4 & P. amboinicus & $0.66 \pm 0.14$ & $0.28 \pm 0.12$ & 0.42 \\
\hline
\end{tabular}

equivalence $\left(R^{2}=0.978\right)$. The highest phenolic content was observed for B. ciliata $(128.44 \pm 0.95)$ followed $R$. aquatica (17.24 \pm 0.16$)$. The least Phenolic content was observed for $P$. amboinicus. Flavonoid content (TFC) also followed the same order. Flavonoid to phenolic ratio was calculated to evaluate the specificity of flavonoid among the total phenolics. A. lanata showed highest $\mathrm{F} / \mathrm{P}$ ratio (0.68) indicating its higher flavonoid abundance out of the total polyphenolics extracted. Phenolic compounds are well known for their numerous biological properties. The differences in the flavonoid structures influence the pharmacological activity and hence it is significant to determine the flavonoid to phenolic ratio [18]. The polyphenolic content of B. ciliata is much higher than that of other studied species and it is in agreement with previous reports $[19,20]$. The phenolic contents of alcoholic extracts of $A$. lanata, $R$. aquatica and $P$. amboinicus have been reported earlier [13, 19, 21], however no literature is available on comparative studies of these species.

\section{HPTLC profiling}

High Performance Thin Layer Chromatography (HPTLC) has become a reliable and effective analytical technique because of its low operating cost and high sample throughput and can be used for the qualitative and quantitative comparison of a group of plant extracts in a single chromatogram. HPTLC profiling of various extracts was done for comparative chemical evaluation of selected species. HPTLC profile showed some similarity in their chemical pattern. At $254 \mathrm{~nm}$, bands at $\mathrm{R}_{\mathrm{f}} 0.07,0.16,0.63$ are common in $\mathrm{BC}$ and RA. At $366 \mathrm{~nm}$, common bands at $0.15,0.31$, and 0.44 were observed in $\mathrm{BC}$ and RA. The correlating $R_{f}$ values of separated bands were further confirmed by the UV absorption recorded by Camag HPTLC scanner. The HPTLC profiling of various extracts of Pashanabheda showed the differences in their chemical constituents and only a few compounds are found to be similar in B. ciliata and R. aquatica Fig. 1.

\section{LC/MS analysis}

Quadrupole Time of Flight Mass Spectroscopy (Q-TOF-MS) is a highly sensitive method for detection,

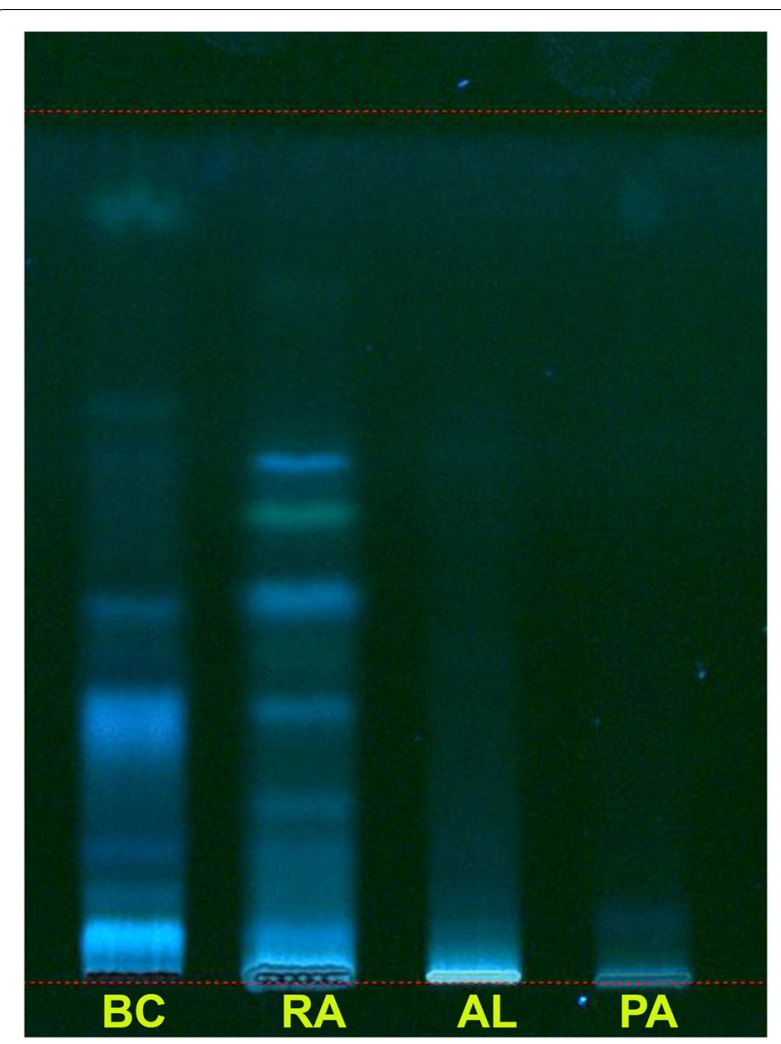

Fig. 1 Comparative HPTLC profile of selected source plants of Pashanabheda at $366 \mathrm{~nm}$

quantitation, and structure elucidation of several compounds in a single analysis. The extracts of selected species were subjected to LC/MS-MS analysis. The molecular ions peaks were extracted to Total Ion Chromatograms (TIC) using Agilent Mass Hunter software. The selection of ions was strictly based on the mass error and ions with more than $2 \mathrm{ppm}$ error with theoretical mass were neglected for further processing. The compounds were tentatively identified on the basis of MS/MS fragmentation pattern obtained by Collision Induced Dissociation (Table 3, Fig. 2). Consistency of mass fragmentation was ensured by targeted mass fragmentation with fixed collision voltage. The structures of compounds were assigned by the putative identification of molecular ions based on mass fragmentation as reported previously [22-24].

LC/MS analysis also showed that major chemical constituents of various species are different in nature, however a few compounds are found to be common. The active marker Berginin was identified only in B. ciliata. A flavanone, 5, 7-dihydroxyflavanone was found in BC, RA and PA. Compounds such as isorhamnetin, dihydro quercetin and 6-hydroxy flavone were identified only in 
Table 3 LC/MS analysis of various source plants of Pashanabheda

\begin{tabular}{llllll}
\hline SI. No & Compound & Molecular formula & $\mathbf{m} / \mathbf{z}[\mathbf{M}-\mathbf{H}]$ & MS/MS & Present in \\
\hline 1 & Gallic acid & $\mathrm{C}_{7} \mathrm{H}_{6} \mathrm{O}_{5}$ & 169.0171 & 125.02 & $\mathrm{BC}, \mathrm{PA}$ \\
2 & Apigenin & $\mathrm{C}_{15} \mathrm{H}_{10} \mathrm{O}_{5}$ & 269.0326 & $149.05,121.06211 .08$ & $\mathrm{BC}$ \\
3 & 5,7-dihydroxyflavanone & $\mathrm{C}_{15} \mathrm{H}_{12} \mathrm{O}_{4}$ & 255.0631 & 183.08 & $\mathrm{BC}, \mathrm{RA}, \mathrm{PA}$ \\
4 & Dihydroquercetin & $\mathrm{C}_{15} \mathrm{H}_{12} \mathrm{O}_{7}$ & 303.1008 & $193.05,149.02$ & $\mathrm{R}$ \\
5 & Protocatechuic acid & $\mathrm{C}_{7} \mathrm{H}_{6} \mathrm{O}_{4}$ & 153.0348 & 109.02 & $\mathrm{CPR}$ \\
6 & Sinapic acid & $\mathrm{C}_{11} \mathrm{H}_{12} \mathrm{O}_{5}$ & 223.0297 & $179.07,135.04$ & $\mathrm{BC}, \mathrm{AL}, \mathrm{PA}$ \\
7 & Caffeic acid & $\mathrm{C}_{9} \mathrm{H}_{8} \mathrm{O}_{4}$ & 179.0375 & $135.04,109.03$ & $\mathrm{BC}, \mathrm{AL}$ \\
8 & Berginin & $\mathrm{C}_{14} \mathrm{H}_{16} \mathrm{O}_{9}$ & 327.0721 & $312.05,234.02$ & $\mathrm{BC}$ \\
9 & Isorhamnetin & $\mathrm{C}_{16} \mathrm{H}_{12} \mathrm{O}_{7}$ & 315.0734 & $152.80,153.69,108.0239$ & $\mathrm{RA}$ \\
10 & 6-Hydroxyflavone & $\mathrm{C}_{15} \mathrm{H}_{10} \mathrm{O}_{3}$ & 237.0421 & $193.07,107.01$ & $\mathrm{RA}$ \\
\hline
\end{tabular}
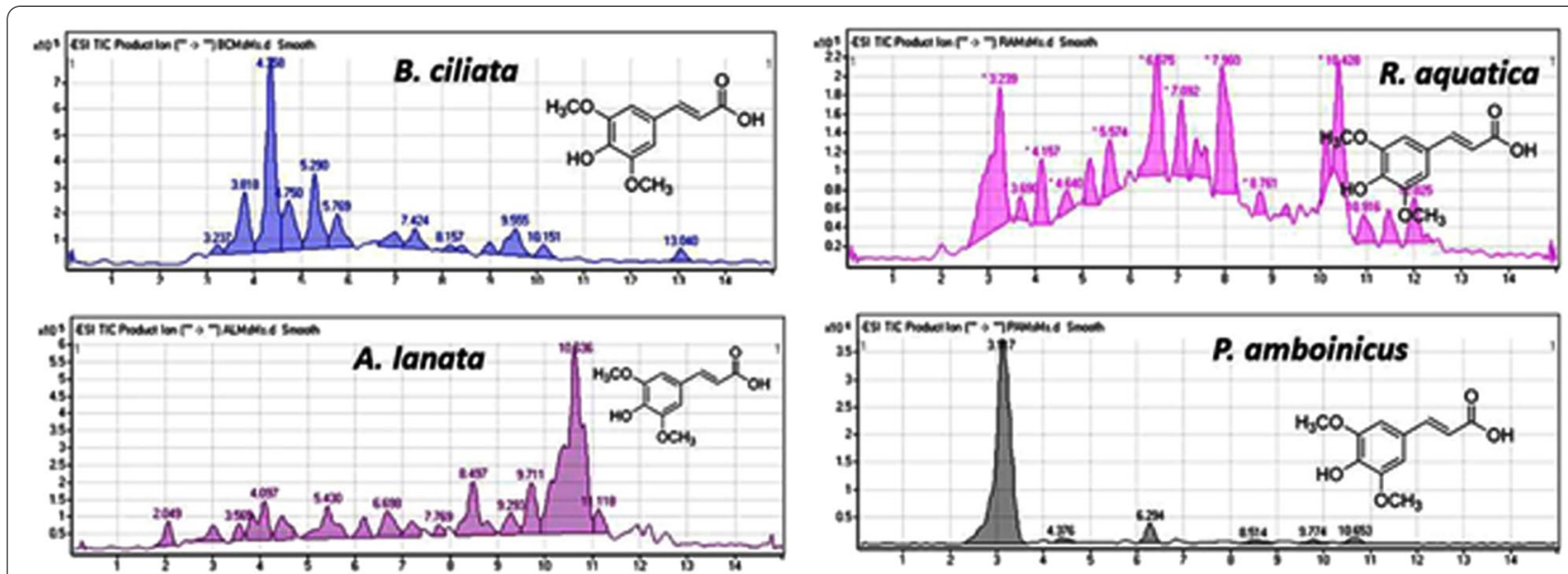

Fig. 2 LC/MS Total Ion Chromatogram (TIC) of selected source plants of Pashanabheda

RA. Metabolite profiling of these species using tandem mass spectroscopy is reporting for the first time.

\section{Acute Oral toxicity study}

There were no deaths, remarkable body weight changes and abnormal clinical signs observed during the study period. In the necropsy studies none of the animals showed any gross lesions. Based on the results of the acute oral toxicity (Acute Toxic Class Method) of the test item, CPR Extract, in Wistar rats, the LD 50 of the test item may be classified as GHS category 5 (LD50 $>2000 \mathrm{mg} / \mathrm{kg}$ ) as per OECD Guideline No. 423, December 2001.

\section{Antiurolithiatic activity \\ Clinical signs and mortality}

There were no abnormal clinical signs and mortalities were observed among study groups throughout the study period in all the groups.

\section{Body weight}

There was no significant difference in the body weight was observed among the study groups throughout the study period (Table 4 ).

\section{Serum biochemistry}

Administration of Ethylene glycol (0.75\%) in drinking water to Disease control animals (G2) induced significant changes in serum urea and creatinine levels when compared to Normal control $(p<0.05)$. Animals treated with Bergenia ciliata extract (BC) at 100 and $200 \mathrm{mg} / \mathrm{kg}$, p.o., (G3 and G4) showed a dose dependent protection against ethylene glycol induced changes in serum urea and creatinine levels (Table 5). Significant protection was observed with high dose $(200 \mathrm{mg} / \mathrm{kg})$ treated group $(P<0.05)$. Groups treated with Aerva lanata extract (AL) at 100 and $200 \mathrm{mg} / \mathrm{kg}$, p.o., showed highest protection among the extracts tested $(p<0.05)$. Animals treated with Rotula aquatica extract (RA) at 100 and $200 \mathrm{mg} /$ $\mathrm{kg}$, p.o. showed only non-significant decrease $(p>0.05)$. 
Table 4 Effect of extracts on body weight (g) in ethylene glycol induced urolithiasis in rats

\begin{tabular}{lllllll}
\hline Group & Treatment & Initial & Week-1 & Week-2 & Week-3 & Week-4 \\
\hline G1:Normal Control & Distilled water 10 ml/kg & $161.1 \pm 17.7$ & $167 \pm 17.9$ & $170.5 \pm 20.5$ & $176.3 \pm 19.9$ & $181 \pm 18.1$ \\
G2: Disease Control & Distilled water 10 ml/kg & $170.8 \pm 13.9$ & $177.6 \pm 15.1$ & $176.8 \pm 17.7$ & $182.1 \pm 17.1$ & $185.8 \pm 17.6$ \\
G3 & BC extract 100 mg/kg & $170.1 \pm 12$ & $172.3 \pm 11.8$ & $182.5 \pm 10.8$ & $186.8 \pm 10.7$ & $190.8 \pm 11.4$ \\
G4 & BC extract 200 mg/kg & $166.5 \pm 12.6$ & $177.1 \pm 5.7$ & $182.1 \pm 7.7$ & $187.1 \pm 9.4$ & $191 \pm 10.5$ \\
G5 & AL extract 100 mg/kg & $176 \pm 6.2$ & $183.1 \pm 5.5$ & $190.1 \pm 6.5$ & $196 \pm 9.5$ & $200.8 \pm 9.8$ \\
G6 & AL extract 200 mg/kg & $167 \pm 11.9$ & $167.6 \pm 11.9$ & $178.5 \pm 13$ & $183.5 \pm 13.9$ & $188.6 \pm 14.9$ \\
G7 & RA extract 100 mg/kg & $169.1 \pm 14.9$ & $174.8 \pm 15.2$ & $180.8 \pm 15.1$ & $185.5 \pm 14.3$ & $191.6 \pm 14.1$ \\
G8 & RA extract 200 $\mathrm{mg} / \mathrm{kg}$ & $163.5 \pm 11.9$ & $168 \pm 10.1$ & $176.6 \pm 11.2$ & $180.8 \pm 12.4$ & $186.3 \pm 11.8$ \\
G9 & PA extract 100 mg/kg & $156.5 \pm 14.5$ & $164.8 \pm 13.1$ & $171.1 \pm 12.4$ & $175.6 \pm 12$ & $180.5 \pm 10.7$ \\
G10 & PA extract 200 mg/kg & $161.8 \pm 16.5$ & $167.8 \pm 15.6$ & $169.8 \pm 12.7$ & $174.8 \pm 12.8$ & $180.8 \pm 11.5$ \\
\hline
\end{tabular}

$\#: p<0.05$ when compared to G1 Normal Control; * $p<0.05$ when compared to G2, Disease control

Table 5 Effect of extracts on serum biochemistry in ethylene glycol induced urolithiasis in rats

\begin{tabular}{llll}
\hline Group & Treatment & BUN (mg/dl) & Creatinine (mg/dl) \\
\hline G1:Normal Control & Distilled water 10 m//kg & $47.5 \pm 13.3$ & $0.9 \pm 0.04$ \\
G2: Disease Control & Distilled water 10 ml/kg & $72.4 \pm 14.7^{\#}$ & $1.24 \pm 0.23^{\#}$ \\
G3 & BC extract 100 mg/kg & $59.2 \pm 13.7$ & $1.11 \pm 0.26$ \\
G4 & BC extract 200 mg/kg & $48.2 \pm 6.0^{*}$ & $0.87 \pm 0.15^{*}$ \\
G5 & AL extract 100 mg/kg & $53.5 \pm 11.9^{*}$ & $0.85 \pm 0.05^{*}$ \\
G6 & AL extract 200 mg/kg & $43.4 \pm 14.7^{*}$ & $0.84 \pm 0.06^{*}$ \\
G7 & RA extract 100 mg/kg & $68.8 \pm 10.3$ & $1.11 \pm 0.23$ \\
G8 & RA extract 200 mg/kg & $55.2 \pm 5.9$ & $1.06 \pm 0.16$ \\
G9 & PA extract 100 mg/kg & $57.4 \pm 10.9$ & $0.89 \pm 0.09^{*}$ \\
G10 & PA extract 200 mg/kg & $44.3 \pm 9.6^{*}$ & $0.87 \pm 0.05^{*}$
\end{tabular}

\#: $p<0.05$ when compared to $\mathrm{G} 1$ Normal Control; * $p<0.05$ when compared to $\mathrm{G} 2$, Disease control

The animals treated with Plectranthus amboinicus extract (PA) at 100 and $200 \mathrm{mg} / \mathrm{kg}$, p.o., showed significant protection only at the high dose $(P<0.05)$.

\section{Urine analysis}

The qualitative urine analysis on day 28 showed a significant induction of crystal urea in Disease control group (G2), when compared to Normal control (G1). In addition to normal urine crystals such as Uric acid and Hippuric acid, the calcium oxalate and phosphate crystals were significantly increased in ethylene glycol treated Disease control group (G2). Treatment with test extracts showed a dose dependent reduction in the calcium oxalate and phosphate crystals. Among the extract treated groups, animals treated with Aerva lanata extract (AL) at 100 and $200 \mathrm{mg} / \mathrm{kg}$, p.o., showed good antiurolithiatic activity.

\section{Histopathology of kidney}

The histopathology analysis showed a significant damage to kidney cells with large amounts of crystal deposits in Disease Control (G2) group treated with ethylene glycol. Animals treated with Bergenia ciliata extract (BC) at 100 and $200 \mathrm{mg} / \mathrm{kg}$, p.o., showed only mild to protection. However, animals treated with Aerva lanata extract (AL) at 100 and $200 \mathrm{mg} / \mathrm{kg}$, p.o., showed good protection with a near normal appearance of the nephrons. Groups G7 and G8; treated with Rotula aquatica extract (RA) at 100 and $200 \mathrm{mg} / \mathrm{kg}$, p.o., showed only mild protection. Groups treated with Plectranthus amboinicus extract (PA) at 100 and $200 \mathrm{mg} / \mathrm{kg}$, p.o., showed mild to moderate protection (Fig. 3). In conclusion, among the tested extracts, Aerva lanata extract at both the tested doses of 100 and $200 \mathrm{mg} / \mathrm{kg}$, p.o., showed significant activity against ethylene glycol induced changes serum and urine biochemistry and also significantly prevented ethylene glycol induced damage to nephrons in Wistar Rats.

\section{Discussion}

The formation of urinary stone is a global health problem that can get to anybody at any age. Men are three times more likely to be affected than women; however, it is an unusual condition in children. Around $0.1-0.4 \%$ of the population suffers with kidney stones every year in the 


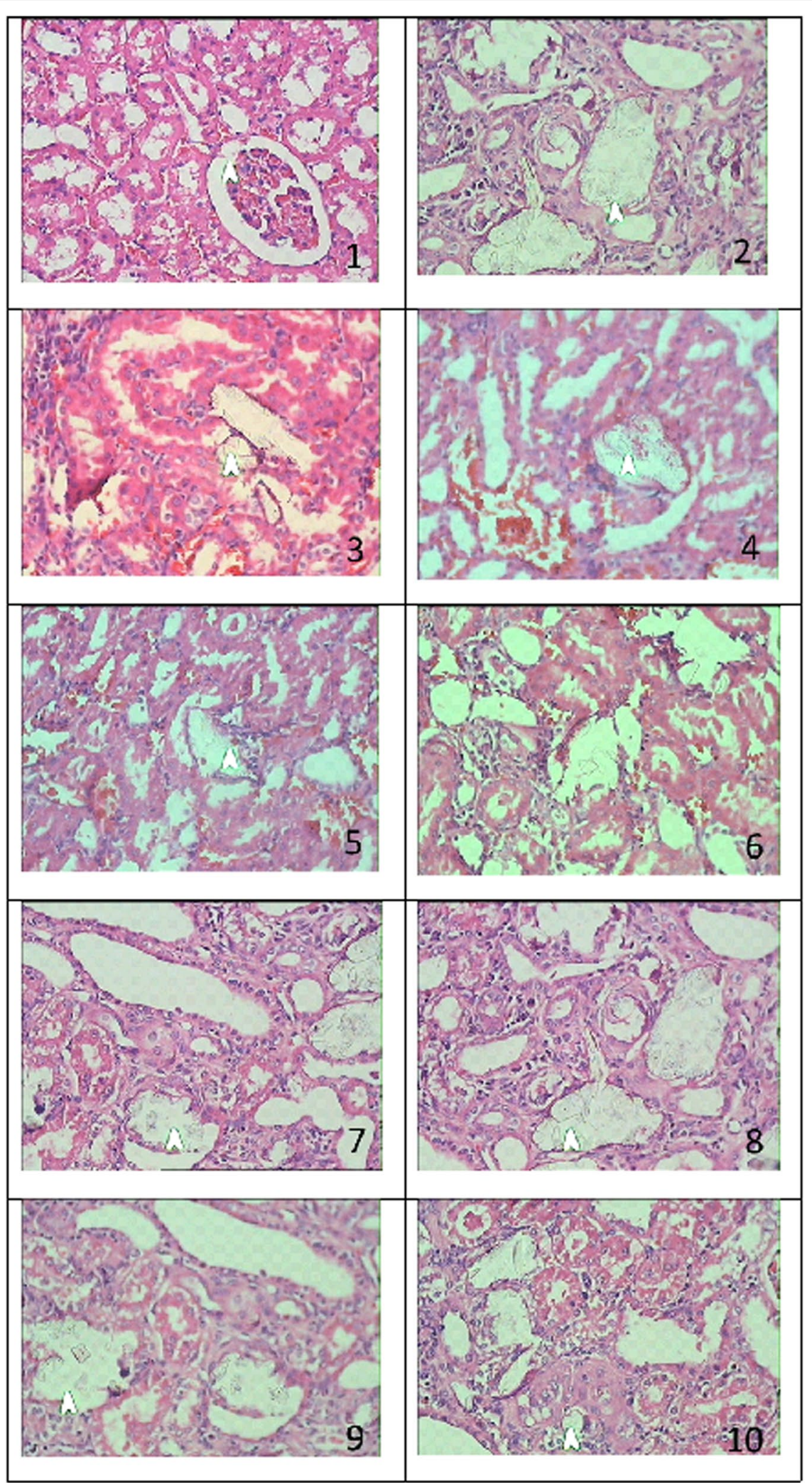

Fig. 3 Histopathology of kidneys of animals treated with selected source plants of Pashanabheda in comparison with control group. 1: Normal Control; 2: Disease control: 3\&4: Treated with BC extracts; 5\&6: Treated with AL extracts; 7\&8: Treated with RA extracts; 9\&10: Treated with PA extracts 
USA and Europe [25]. It is estimated that about 2-5\% of the population in Asia, 8-15\% in Europe and North America, and 20\% in Saudi Arabia develop urinary stones in their lifetime and the risk of recurrence is also high. It has been found that about $50 \%$ of patients will experience a recurrence of stone within 10 years after the initial episode [26]. In most of the urinary calculi cases, patients have to treat with modern interventional procedures which are not easily assessable, and almost not suitable for patients with high urinary stone recurrence rate. On this context, herbal medicines are found to be effective, as well as easily available and economical.

In Ayurveda, medicinal plants have been classified according to pharmacological action. Pashanabheda (Pashana-stone; Bheda-break) is a term used for a group of plants with diuretic and antiurolithiatic activities [27]. The botanical identity of this drug is in a controversial status as various plants are being used as Pashanabheda in different parts of the country. The most essential criteria for validating herbal drug are pharmacological activity rather than morphology or phytoconstituents. Chemical profiles of the selected source plants were compared by HPTLC analysis. Metabolite characterization was done by liquid chromatography based tandem mass spectroscopic evaluation. Major Phytochemicals such as phenolics and flavonoids were estimated spectrophotometrically. Even though no significant phytochemical correlation was observed between B. cilita and A. lanata, they possessed significant antiurolithiatic activity when compared to other species. This indicates that similar bioactivities could be obtained from unrelated species even when the chemical composition and botanical identities may not be the same. The biological properties like anti-bacterial, anti-inflammatory, antioxidant and antiurolithiatic activity of selected species were reported earlier [3, 28], however comparative pharmacological evaluation of these species has not been reported yet. The study also validated the traditional knowledge base of Ayurveda for the treatment urolithiasis.

\section{Conclusion}

Ayurvedic literature describe herbs with synonyms, which do not exactly specify the botanical source but attribute to therapeutic utility of the plant and hence, under one name, different plants are known in different parts of the country as per the depiction which makes the drug controversial. Pashanabheda is one of such controversial drugs used in Ayurveda. Comparative phytochemical and pharmacological studies of controversial drug are a novel idea as it provides valuable information about the scientific base of its traditional use. Different botanical sources such as Bergenia ciliata, Rotula aquatica, Aerva lanata, and Plectranthus amboinicus are used in the name of Pashanabheda. The present study was focused on phytochemical and pharmacological comparison of different source plants used as Pashanabheda. Phytochemical studies revealed that most of the chemical constituents are different in different species. Only a few common compounds have been identified in various species. Pharmacological study showed that Aerva lanata is the most active species against ethylene glycol induced nephrolithiasis in tested animals. A. lanata showed significant dose depended antiurolithiatic activity compared to all other species. The study concluded the possibility of using Aerva lanata as a scientifically validated substitute for Pashanabheda and these findings have provided scientific basis for the use of traditionally used medicinal plants for urolithiasis.

\section{Acknowledgements}

The authors are thankful to Dr. T K Praveen, Professor, JSS College of Pharmacy, Ooty, Tamil Nadu, India for the support in Pharmacological evaluation.

\section{Conflict of interest}

The authors declare that there are no conflicts of interest.

\section{Authors' contributions}

SCT: Designed the study carried out LC/MS analysis, pharmacological evaluation and drafted the manuscript. JCK: Carried out the phytochemical analysis. JKU: Participated in the phytochemical analysis. PKM: Collected the plant materials. IB: Participated in study designing and edited the manuscript. The author(s) read and approved the final manuscript.

\section{Funding}

The study was supported by National Medicinal Plants Board, Ministry of AYUSH, Government of India (Project \# R\&D/KE-01/2015-16).

Availability of data and materials

The data will be made available on request.

\section{Declarations}

Ethics approval and consent to participate

The study protocol was approved by the ethical guidelines of CPCSEA after obtaining necessary clearance from the committee (JSSCP/OT/ IAEC/05/2018-19).

\section{Consent for publication}

The authors permitted to publish this work in Clinical Phytoscience.

\section{Competing interests}

The authors declare that there is no conflict of interests regarding the publication of this paper.

Received: 27 March 2020 Accepted: 18 February 2022

Published online: 07 March 2022

References

1. Atmani F, Slimani Y, Mimouni M, Aziz M., Hacht B, . Ziyyat A (2004) Effect of aqueous extract from Herniaria hirsuta L. On experimentally nephrolithiasic rats. J Ethnopharmacol 95 (1): 87-93.

2. Vyas N, Kesearvani RK, Jain S, Raghuvanshi R, Gavatia NP. Urolithiasis and its management. Pharm Lett. 2010;2(1):457-46.

3. Dinnimath BM, Jalalpure SS, Patil UK. Antiurolithiatic activity of natural constituents isolated from Aerva lanata. J Ayurveda Integr Med. 2017;8(4):226-32 
4. Madhavan V, Goswami KP, Gurudeva MR, Yoganarasimhan SN. Pharmacognostical studies on the root of Nothosaerva brachiata Wt. - a botanical source of the Ayurvedic drug, Pashanabheda. Indian J Tradit Knowl. 2010;9(4):629-34.

5. Dhalwal KV, Shinde M, Biradar YS, Mahadik KR. Simultaneous quantification of bergenin, catechin, and gallic acid from Bergenia ciliata and Bergenia ligulata by using thin-layer chromatography. J Food Compos Anal. 2008;21(6):496-500.

6. Vyas N, Argal A. Antiurolithiatic activity of extract and Oleanolic acid isolated from the roots of Lantana camara on zinc disc implantation induced Urolithiasis. Int Sch Res Notices. 2013. https://doi.org/10.1155/ 2013/951795.

7. Soundararajan P, Mahesh R, Ramesh T, Begum VH. Effect of Aerva lanata on calcium oxalate urolithiasis in rats. Indian J Exp Biol. 2006;44(12):981-6 PMID: 17176671.

8. Goyal M, Pareek A, Nagori BP, Sasmal D. Aerva lanata: a review on phytochemistry and pharmacological aspects. Pharmacogn Rev. 2011;5(10):195-8.

9. Behera PC, Ghosh M. Evaluation of antioxidant, antimicrobial, and antiurolithiatic potential of different solvent extracts of Aerva lanata Linn flowers. Pharmacogn Mag. 2018;14(53):53-7.

10. Warrier PK, Nambiar VPK, Ramankutty C. Indian medicinal plants, vol. 4. 1st ed. Madras: Orient Longman Limited; 1995. p. 315-7.

11. Sasikala $V$, Radha SR, Vijayakumari B. In vitro evaluation of Rotula aquatica Lour. For antiurolithiatic activity. J Pharm Res. 2013;6(3):378-82.

12. Chopra RN, Nayar SL, Chopra IC. The glossary of Indian medicinal plants. New Delhi: CSIR; 1956. p. 74.

13. Sulaiman CT, Deepak M, Balachandran I. Spectrophotometric and tandem mass spectroscopic analysis of Indian borage (Plectranthus amboinicus (Lour.) Spreng.) for its polyphenolics characterization. BeniSuef Univ J Basic Appl Sci. 2018;7(4):471-3.

14. Singleton VL, Rossi JA Jr. Colorimetry of total phenolics with phosphomolybdic phosphotungstic acid reagents. Ame J Eno Viticulture. 1965;16:144-58.

15. Zhishen J, Mengcheng T, Jianming $W$. The determination of flavonoid contents in mulberry and their scavenging effects on. Superoxide Radic Food Chem. 1999;64:555-9.

16. Sulaiman CT, Thushar KV, George S, Balachandran I. Phenolic characterization of selected Salacia species using LC-ESI-MS/MS analysis. Nat Prod Res. 2014;28:1021-4.

17. Sulaiman CT, Jyothi CK, Unnithan JK, Prabhukumar KM, Balachandran I. Identification of validated substitute for Asoka (Saraca asoca (Roxb.) Willd.) by phytochemical and pharmacological evaluations, Futur. J Pharm Sci. 2020:6:10. https://doi.org/10.1186/s43094-020-00024-2.

18. Sulaiman CT, Ramesh PR, Mahesh K, Anandan EM, Praveen M, Balachandran I. Metabolite profiling of Cyanthillium cinereum (L.) H. rob. And its herbal formulation by tandem mass spectroscopic analysis, natural product research. 2021. https://doi.org/10.1080/14786419.2020.1869972.

19. Sulaiman CT, Balachandran I. Total phenolics and total flavonoids in selected Indian medicinal plants. Indian J Pharm Sci. 2012;74(3):258-60.

20. Singh M, Pandey N, Agnihotri V, Singh KK, Pandey A. Antioxidant, antimicrobial activity and bioactive compounds of Bergenia ciliata Sternb.: a valuable medicinal herb of Sikkim Himalaya. J Tradit Complement Med. 2017;7(2):152-7.

21. Pandey R, Kumar B, Meena B, Srivastava M, Mishra T, Tiwari V, et al. Major bioactive phenolics in Bergenia species from the Indian Himalayan region: method development, validation and quantitative estimation using UHPLC-QqQLIT-MS/MS. PLoS One. 2017. https://doi.org/10.1371/ journal.pone.0180950.

22. Pallavi M, Ramesh CK, Krishna V, Channakeshava GH, Jamuna K. Total Phenolics and antioxidant potentials of Rotula aquatica Lour. J App Pharm Sci. 2016;6(04):169-74.

23. Lin LZ, Harnly JM. Identification of the phenolic components of chrysanthemum flower (Chrysanthemum morifolium Ramat). Food Chem. 2010;120:319-26.

24. Ibrahim RM, El-Halawany AM, Saleh DO, Naggar EMBE, El-Shabrawy AERO, El-Hawary SS. HPLCDAD-MS/MS profiling of phenolics from Securigera securidaca flowers and its anti-hyperglycemic and anti-hyperlipidemic activities. Rev Bras. 2015;25:134-41.
25. Deepak MK, Suresh DJ, Dinesh T, Mahendra SK, Wendy RR. Herbal remedies for urinary stones used in India and China: a review. J Ethnopharmacol. 2017;203(5):55-68.

26. Yu L, Chen Y, Liao B, Luo D, Wang K, Li H, et al. Epidemiology of urolithiasis in Asia. Asian J Urol. 2018;5(4):205-14.

27. Sulaiman CT, Balachandran I. LC/MS characterization of antioxidant flavonoids from Tragia involucrata L. Beni-suef Univ J Basic Appl Sci. 2016;5:231-5.

28. Ahmad M, Butt MA, Zhang G, Sultana S, Tarigd A, Zafar M. Bergenia ciliata: a comprehensive review of its traditional uses, phytochemistry, pharmacology and safety. Biomed Pharmacother. 2018;97:708-21.

\section{Publisher's Note}

Springer Nature remains neutral with regard to jurisdictional claims in published maps and institutional affiliations.

\section{Submit your manuscript to a SpringerOpen ${ }^{\circ}$ journal and benefit from:}

- Convenient online submission

- Rigorous peer review

- Open access: articles freely available online

- High visibility within the field

- Retaining the copyright to your article

Submit your next manuscript at $\boldsymbol{\nabla}$ springeropen.com 